Article

\title{
On the Effect of Natural Aging Prior to Low Temperature ECAP of a High-Strength Aluminum Alloy
}

\author{
Sebastian Fritsch * and Martin Franz-Xaver Wagner \\ Chair of Materials Science, Institute of Materials Science and Engineering, Technische Universität Chemnitz, \\ 09125 Chemnitz, Germany; martin.wagner@mb.tu-chemnitz.de \\ * Correspondence: sebastian.fritsch@mb.tu-chemnitz.de; Tel.: +49-371-531-37441
}

Received: 21 December 2017; Accepted: 16 January 2018; Published: 18 January 2018

\begin{abstract}
Severe plastic deformation (SPD) can be used to generate ultra-fine grained microstructures and thus to increase the strength of many materials. Unfortunately, high strength aluminum alloys are generally hard to deform, which puts severe limits on the feasibility of conventional SPD methods. In this study, we use low temperature equal-channel angular pressing (ECAP) to deform an AA7075 alloy. We perform ECAP in a custom-built, cooled ECAP-tool with an internal angle of $90^{\circ}$ at $-60^{\circ} \mathrm{C}$ and with an applied backpressure. In previous studies, high-strength age hardening aluminum alloys were deformed in a solid solution heat treated condition to improve the mechanical properties in combination with subsequent (post-ECAP) aging. In the present study, we systematically vary the initial microstructure-i.e., the material condition prior to low temperature ECAP—by (pre-ECAP) natural aging. The key result of the present study is that precipitates introduced prior to ECAP speed up grain refinement during ECAP. Longer aging times lead to accelerated microstructural evolution, to increasing strength, and to a transition in fracture behavior after a single pass of low temperature ECAP. These results demonstrate the potential of these thermo-mechanical treatments to produce improved properties of high-strength aluminum alloys.
\end{abstract}

Keywords: equal-channel angular pressing (ECAP); low temperature; cryogenic deformation; SPD-processes; high strength aluminum alloy; AA7075; AlZnMgCu-alloy; ultra-fine grained (UFG)

\section{Introduction}

Severe plastic deformation (SPD) methods allow the generation of ultra-fine grained (UFG) microstructures [1,2]; equal-channel angular pressing (ECAP) is one of the most successful SPD approaches to produce high strength combined with good ductility in various metals and alloys [3-7]. The increase of strength is due to grain-refinement processes into the sub-micrometer range. In regions of high dislocation densities, low-angle grain boundaries are formed and then further transformed into high-angle grain boundaries, which leads to a reduction of grain size by cold work [8-10]. ECAP processing has been used to increase the strength of various age hardening aluminum alloys. Typically, these alloys are deformed in the solution heat treated condition at room temperature (RT), mainly for two reasons: (i) to increase the workability during the SPD process and (ii) to form homogeneously distributed precipitates in a subsequent (i.e., post-ECAP) heat treatment to further improve the mechanical properties of the material. However, there are some difficulties with ECAP processing of high-strength aluminum alloys such as AA7075; in previous studies, we discussed why ECAP at RT of this material leads to the formation of shear bands and to subsequent cracking [11,12]. Increasing the workability by increasing the deformation temperature up to about $100{ }^{\circ} \mathrm{C}$ does in principle allow a successful production of homogenous billets, but the mechanical properties are hardly improved because of increased recovery processes [13]. 
There is, however, a viable approach to increase the strength of hard to deform face-centered cubic (fcc) metals based on the insights of physical metallurgy: to considerably increase the dislocation density during deformation (and thus to benefit from grain size reduction), dynamic recovery processes need to be suppressed during the deformation process [14,15]. This can be achieved by performing SPD at low (or even cryogenic) temperatures, where the strain hardening capability of fcc metals is increased and strain localization and crack formation can be suppressed. Additionally, cross slip and dislocation annihilation processes are prevented because of the limited mobility of defects at low temperatures. This leads to an improved ductility and workability, specifically because the strain hardening stages III and IV are considerably extended [11,12]. The most well-known process that exploits the advantages of low temperature deformation is cryogenic rolling. This is a relatively simple procedure which can be performed in conventional roller mills. To ensure a limited increase of temperature because of plastic work, the materials typically need to be deformed in small incremental steps. They are typically cooled in liquid nitrogen, then placed into the rolling mill and subsequently deformed-typically by true plastic strains of about 0.1 per rolling step. For SPD, these steps therefore have to be repeated several times [5,16-18]. Using this procedure, accumulated true plastic strains of about three have been achieved in high strength aluminum alloys [13,19], which resulted in a strong increase of initial flow stress and a somewhat increased ductility when cryogenic rolling was combined with a suitable post-rolling heat treatment. Rolling of course always leads to plate geometries, which is a limiting parameter for the use of a material in technological applications that require bulk billets. Multidirectional forging [20] and ECAP [8-10] at low temperatures allow for SPD processing of bulk materials under well-defined deformation conditions. Especially ECAP, which conserves the cross section of the billets, allows for careful control of the deformation velocity and facilitates application of an active backpressure, offers great potential to further develop low temperature SPD processing.

Another important aspect in ensuring that ECAP can be performed on high strength aluminum alloys is to reduce dynamic strain aging. This microstructural effect is the result of the interaction between dislocations and solute atoms. Dynamic strain aging can be observed as serrated flow in the corresponding stress-strain curves and leads to the formation of deformation bands. These bands are macroscopically visible on the surface of tensile specimens. The mechanism is well known as Portevin-Le Chatelier effect (PLC effect) and is related to thermally activated processes. The formation of PLC bands therefore strongly depends on temperature and strain rate. In summary, many aluminum alloys exhibit a better formability at low temperatures because of two effects: an increased strain-hardening rate and suppressed PLC effects. Previous studies have shown that $-60{ }^{\circ} \mathrm{C}$ is a suitable temperature for successful ECAP processing of high strength aluminum alloys [12]. This temperature increases the ductility of the material by about $60 \%$ compared to the ductility at RT and dramatically reduces the susceptibility for discontinuous flow.

Besides the deformation temperature, the formation of precipitates after the solution heat treatment influences the occurrence of PLC effects. These strengthening precipitates can already be formed at RT, depending on aging time. Because of the high amount of copper, the alloy AA7075 is prone to an early formation of Guinier-Preston (GP) zones even at RT. Already very short natural aging times (10 $\mathrm{min}$ ) can strongly influence the onset of serrated flow; with increasing natural aging time, the first serrations are shifted to higher stress/strain values, which also affects subsequent crack initiation and failure of the specimen. After the formation of a sufficiently larger volume fraction of GP zones, strain localization can be entirely suppressed because the higher amount of GP zones leads to a decreased density of mobile point defects [12,21].

The microstructure of the AA7075 alloy is strongly influenced by natural aging after a solution heat treatment, already within very short times. In the present study, we consider this important aspect, and we discuss how the formation of precipitates prior to ECAP influences the workability at low deformation temperatures. Furthermore, we show how the microstructure of the aluminum alloy AA7075 is affected by the deformation process depending on the amount of precipitates formed 
prior to processing. Finally, we discuss how these microstructural changes influence the mechanical properties after low temperature ECAP.

\section{Materials and Methods}

The aluminum alloy AA7075 was obtained from KUMZ, (Kamensk Uralsky, Russia), as an extruded bar with a cross-section of $15 \times 15 \mathrm{~mm}^{2}$. The chemical composition was $5.9 \mathrm{Zn}-2.3 \mathrm{Mg}-1.3 \mathrm{Cu}-0.2 \mathrm{Fe}-0.1 \mathrm{Si}$ wt \%. The material was solutionized at $475{ }^{\circ} \mathrm{C}$ for $2.25 \mathrm{~h}$ and subsequently water-quenched to RT. Afterwards, the solutionized material was naturally aged between $1 \mathrm{~min}$ and $24 \mathrm{~h}$ at RT, followed by ECAP-processing (the internal angle was $90^{\circ}$, which corresponds to an equivalent plastic strain of 1.1) at $-60^{\circ} \mathrm{C}$ in a custom-built ECAP die for one pass. The pressing speed was $20 \mathrm{~mm} / \mathrm{min}$ and a backpressure of $176 \mathrm{MPa}$ was applied to suppress shear localization or failure by cracking. The billets were covered with the lubricant Aero Shell Grease 33MS (molybdenum disulphide) to minimize friction. Detailed information about the design and functionality of the setup for low temperature ECAP, and about the choice of deformation parameters is given in our previous publications [12,22].

After processing, the material was fully naturally aged. In order to characterize the natural aging of the material, hardness measurements (Brinell hardness 2.5/62.5) were conducted in the longitudinal plane of the billets after different aging times. Average hardness values and standard deviations were calculated from five indents. For further mechanical characterization, tensile tests using a Zwick/Roell $20 \mathrm{kN}$ tensile testing machine (Ulm, Germany) were performed on ECAP-processed conditions with different aging times (between $1 \mathrm{~min}$ and $24 \mathrm{~h}$ ) prior to ECAP. The miniaturized tensile specimens had a gauge length of $5 \mathrm{~mm}$ with a cross section of $2 \times 2 \mathrm{~mm}^{2}$ and were tested at RT with an initial strain rate of $10^{-3} \mathrm{~s}^{-1}$. Strains were determined with an optical digital image correlation system (Aramis by GOM, version 6.3.1, Braunschweig, Germany). This technique measures the displacement fields of a speckle pattern on the specimen surface. The surface deformation field is recorded during the test and can subsequently be used to determine uniaxial strains. For statistics, five specimens of each condition were tested. Typical microstructural features of the different material conditions were analyzed by transmission electron microscopy (TEM) in a H8100 (Hitachi, Tokyo, Japan) operated at $200 \mathrm{kV}$. The TEM samples were cut parallel to the processing direction and were first twin jet electro-polished and then polished using an argon-ion-beam. Finally, the fracture surfaces were investigated in a field emission scanning electron microscope (NEON40 by Zeiss, Jena, Germany). The acceleration distance was $5 \mathrm{kV}$ with an operating distance of $4 \mathrm{~mm}$. Besides the detector for secondary and back-scattered electrons, an in-lens detector was used because it provides an enhanced contrast that improves the analysis of fracture surfaces.

\section{Results and Discussion}

There is a strong tendency for the formation of strength increased precipitates during natural aging in the solution heat treated condition of high strength age hardening aluminum alloys. This effect can be demonstrated with simple hardness measurements. Figure 1 shows the evolution of hardness (HBW) of AA7075 after solutionizing, followed by natural aging at RT, compared to aging at $-30{ }^{\circ} \mathrm{C}$. The initial hardness values are about $88 \mathrm{HBW}$. A few minutes of natural aging already lead to a slight increase of hardness. After two hours, the hardness reaches a value of about $96 \mathrm{HBW}$. With a further increase of aging time, the hardness steadily increases. After $24 \mathrm{~h}$ of natural aging, hardness reaches a value of about $135 \mathrm{HBW}$. This is an increase of approx. 50\% compared to the initial hardness value. This strong increase of hardness is due to the early formation of GP zones which is promoted by the high amount of copper. In comparison, aging at $-30{ }^{\circ} \mathrm{C}$ suppresses the formation of precipitates which leads to a constant hardness. Therefore, deformation at a low temperature provides a couple of advantages - the strain hardening capability is increased, strain localization and crack formation can be suppressed, and the influence of precipitates (formed by natural aging prior to low temperature ECAP) on microstructural changes can be systematically investigated. 


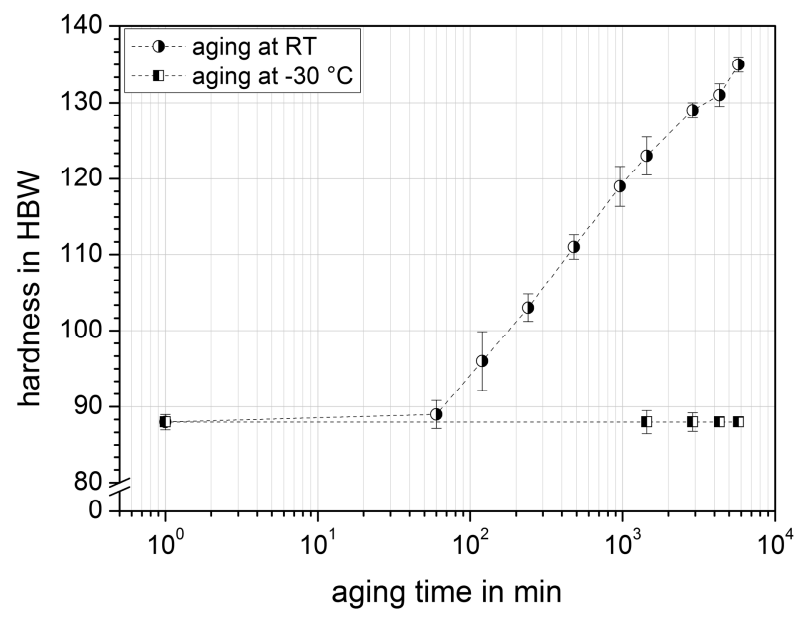

Figure 1. Evolution of hardness of the aluminum alloy AA7075 after solution heat treatment with subsequent aging at room temperature (RT) and at $-30{ }^{\circ} \mathrm{C}$. Lower temperatures suppress the formation of strength-increasing precipitates and leads to constant values of hardness compared to RT aging even after relatively long aging times.

In order to characterize the effect of the thermo-mechanical treatments studied here, we briefly discuss the correlation between processing parameters (specifically, the natural aging time prior to ECAP) and the corresponding microstructures. Figure 2 shows typical TEM bright field images of the conventional peak aged condition compared to the deformed material. The grain size of the conventional peak aged condition is about 4-7 $\mu \mathrm{m}$ (Figure 2a). As reported in [11] this condition shows nano-scaled precipitates in the matrix, with a size ranging from 5 to $15 \mathrm{~nm}$ and a platelet shape. The precipitates are homogenously distributed inside the grains. They become coarser and more sparsely distributed near the grain boundaries. In these regions, precipitation free zones with width of about $30 \mathrm{~nm}$ can be observed. The fine-grained microstructures after one ECAP pass at $-60{ }^{\circ} \mathrm{C}$ are shown in Figure $2 b-d$. The large shear deformation immediately after solutionizing (this material condition is referred to as aged for $1 \mathrm{~min}$ throughout this paper, Figure $2 \mathrm{~b}$ ) results in the formation of characteristic shear bands with a width of approximately one micron. The dislocation density is considerably increased. This mechanism leads to the onset of recovery processes by formation of wall-like substructures. These sub-grain structures influence the final grain-size after SPD [23-26]. Characteristic regions in the TEM images can be identified as low angle grain-boundaries [27,28]. Adjacent to these dark areas with a high dislocation density, some regions appear much brighter, which corresponds to a much lower dislocation density. The microstructure exhibits a bimodal character. It is well known that the shear deformation during ECAP processing can be partitioned into regions with high and low deformation. These distinct regions are delimited by high-angle grain boundaries, which can already be formed locally after a single ECAP pass. As a result of natural aging $(8 \mathrm{~h}$, Figure $2 \mathrm{c})$, strengthening precipitates (GP zones) are formed. Consequently, more dislocations are pinned during ECAP processing. This leads to a more pronounced formation of cell walls and sub-grain structures (Figure 2c). Therefore, the area fraction of less severely deformed regions decreases. This also leads to an increased number of high-angle grain boundaries, which can be observed in the severely deformed areas in Figure 2c. We note that the microstructure exhibits a similar grain-size distribution as material after ECAP processing with three passes without natural aging prior to the deformation, as reported in [22]. After natural aging for $24 \mathrm{~h}$ prior to ECAP, the dislocation density as well as the formation of sub-grain structures are further increased (Figure 2d). Regions with less shear deformation have almost disappeared. The microstructure is homogeneous, with an increased number of fine-grained regions compared to the conditions with shorter pre-ECAP aging times. This grain-size distribution after only one ECAP-pass is similar to a severely deformed condition after four passes, see also [22]. The TEM results summarized in Figure 2 clearly show that natural aging prior to ECAP 
can strongly influence the microstructural evolution. This effect is obviously related to the formation of GP zones, which leads to an increased number of stored and pinned dislocations, and which further results in increased dislocation densities and in the early formation of fine-grained microstructures.
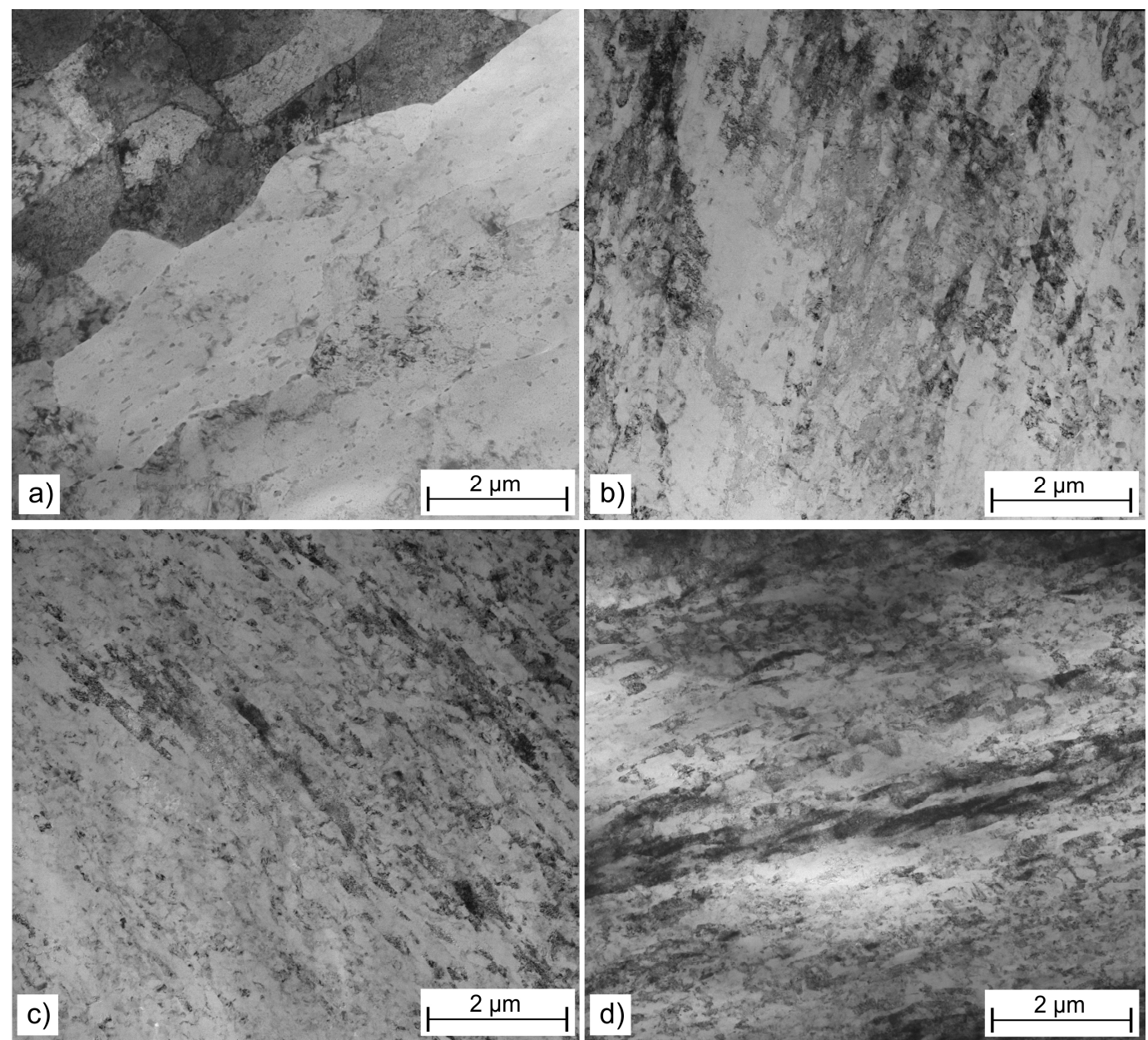

Figure 2. Transmission electron microscopy (TEM) bright field images of the AA7075 alloy in (a) conventional peak-aged condition with an average grain size of about 4-7 $\mu \mathrm{m}$ compared to the as-processed material after equal-channel angular pressing (ECAP). The material was deformed in the solutionized heat treated condition, with RT aging (prior to ECAP) for (b) $1 \mathrm{~min}$; (c) $8 \mathrm{~h}$ and (d) $24 \mathrm{~h}$. The increase of pre-ECAP natural aging time results in a homogeneous grain refinement with a distinct sub-grain microstructure.

The conventional concept of grain refinement as the result of the accumulation of dislocations and the formation of sub-grain structures and new grains is well known; the schematic illustration in Figure 3 extends this view to provide a broader picture of the relationship between grain refinement processes and precipitates formed prior to ECAP. Figure 3a represents a precipitation free, solid solution heat treated condition with some high-angle grain boundaries. Typically, SPD (like ECAP) processing of such material conditions allow generating (ultra)fine-grained microstructures, at first driven by the formation of subgrains. Natural aging prior to ECAP leads to the formation of GP zones (Figure 3b). Dislocations are pinned by these GP zones during the deformation. This leads to an increased dislocation density and a much more pronounced sub-grain network even after a single ECAP pass. With increasing natural aging times prior to deformation, the number of precipitates is further increased (Figure 3c), which provides additional points to pin dislocations, and again intensifies the formation of sub-grain structures and the grain refinement process. 


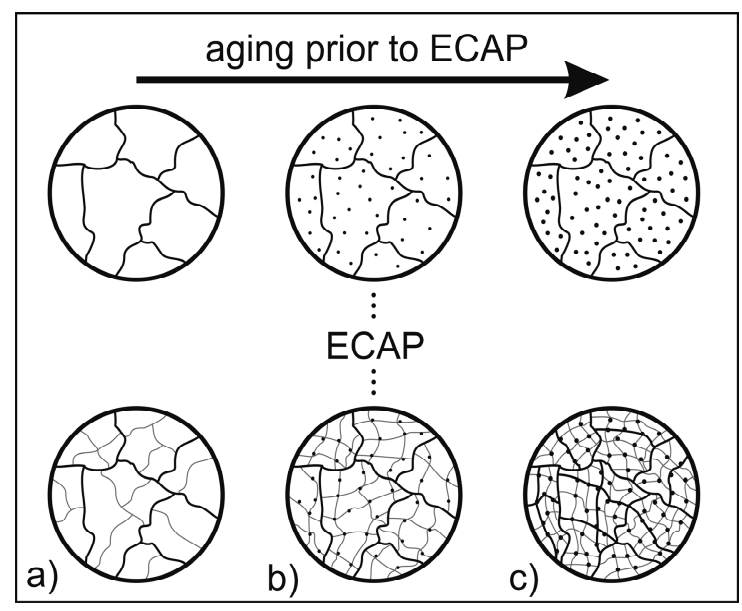

Figure 3. Schematic representation of the modified grain refinement process as a result of the formation of precipitates prior to severe plastic deformation (SPD) processing. Figures in the top row indicate the formation of precipitates as a function of increasing aging times. The images below show how the precipitates influence the grain refinement process during subsequent ECAP: (a) in the solution heat treated condition, the formation of sub-grain structures primarily results from dislocation interactions; (b) dislocations are additionally pinned by the precipitates formed before, which results in the formation of additional sub-grains; (c) longer aging times lead to an increased number of precipitates and further promotes the formation of dislocation networks and sub-grains after only one ECAP pass.

The modified microstructures of course have a strong influence on the mechanical properties of the material conditions that have been naturally aged prior to ECAP. In order to further characterize the effects of the thermomechanical treatments studied here, we briefly discuss the relation between microstructure and the corresponding mechanical properties. Figure 4 shows characteristic (engineering) stress-strain curves of the material conditions that were processed by ECAP and that were subjected to natural aging prior to the deformation for $1 \mathrm{~min}, 8 \mathrm{~h}$ and $24 \mathrm{~h}$, respectively. An increased natural aging time results in a strong increase of strength while ductility is decreased. After performing a large number of tensile tests on different material conditions, characteristic mechanical parameters were determined. They are shown as a function of natural aging time prior to ECAP in Figure 5 (Figure 5a: strength values; Figure 5b, strain values). These data allow evaluating the aging kinetics. Tensile testing after solutionizing (labeled again as an aging time of $1 \mathrm{~min}$ ) results in a yield strength (YS) of about $500 \mathrm{MPa}$ (Figure 5a). YS remains almost constant for short pre-aging times up to about $2 \mathrm{~h}$. The ultimate tensile strength (UTS) shows a similar behavior, with values of about $580 \mathrm{MPa}$. With increasing natural aging times, the strength increases continuously. After 720 min the yield strength and ultimate tensile strength values reach saturation values of about 550 and $630 \mathrm{MPa}$, respectively. This corresponds to an increase of about $10 \%$ compared to the conventional peak aged condition-we highlight that this is a noteworthy improvement since no post-ECAP heat treatment (which is typically used to further modify mechanical behavior) was used. The ductility is almost constant up to natural (pre-ECAP) aging times of $2 \mathrm{~h}$ (Figure 5b). Compared to the conventional peak aged condition, uniform elongation (UE) and elongation to failure (EF) values are slightly higher with increases of $9 \%$ and $12 \%$, respectively. Further increased aging times lead to a pronounced decrease of ductility. Uniform elongation values drop rapidly with increasing pre-ECAP aging times. After $24 \mathrm{~h}$ of natural aging prior to ECAP, elongation to failure is less than $4 \%$, so that necking could not even be observed. In summary, the microstructural changes associated with natural aging, specifically the nucleation of GP zones, clearly affect the mechanical properties of the material conditions studied here. An increasing volume fraction of GP zones during the natural aging process fully rationalizes the observed increases of hardness and strength (Figures 1 and $5 \mathrm{a}$ ) as well as the reduction of ductility (Figure 5b). 


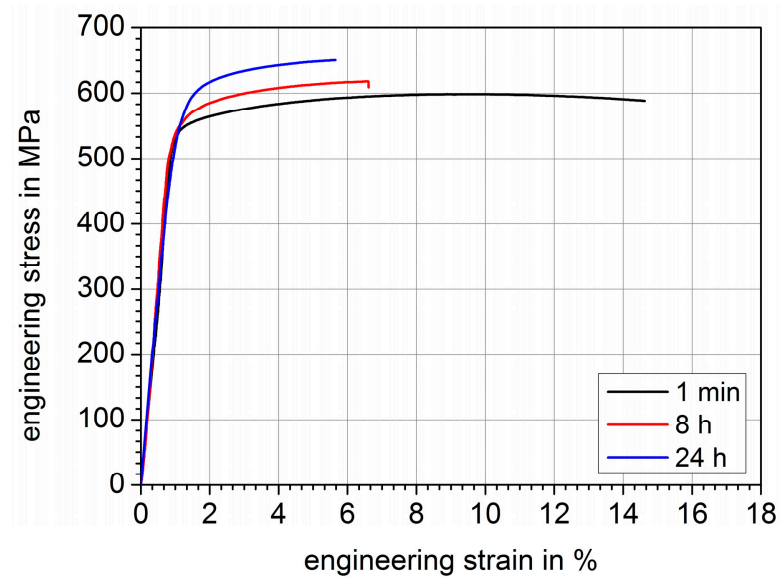

Figure 4. Characteristic engineering stress-engineering strain curves of AA7075 under quasi static loading at RT. Samples were naturally aged for $1 \mathrm{~min}, 8 \mathrm{~h}$ or $24 \mathrm{~h}$ prior to ECAP. Increasing the natural aging time prior to deformation results in increased strength and reduced ductility after one ECAP pass.

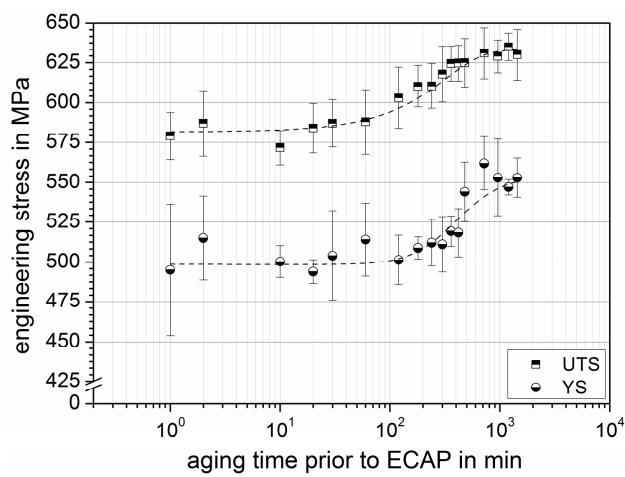

(a)

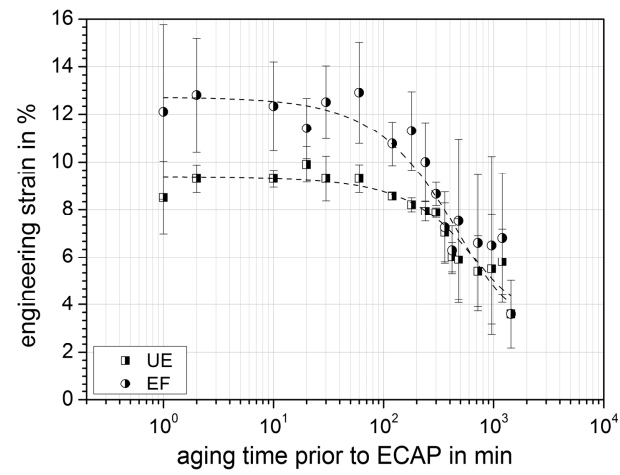

(b)

Figure 5. Characteristic values of (a) engineering stress and (b) engineering strain depending on aging at RT prior to ECAP in the solution heat treated condition for one pass at $-60^{\circ} \mathrm{C}$. The increase of natural aging time prior to ECAP results in an increase of ultimate tensile strength (UTS) and yield strength (YS), while the ductility (uniform elongation (UE) and elongation to failure (EF)) is decreased.

The changes in terms of microstructural features and of the mechanical properties can also be directly related to an analysis of the corresponding fracture surfaces. The results of the SEM investigations are presented in Figure 6, with a focus on two representative material conditions: ECAP directly after solutionizing (Figure $6 \mathrm{a}, \mathrm{c}, \mathrm{e}$ ) versus pre-ECAP aging of $24 \mathrm{~h}$ aging at RT (Figure $6 \mathrm{~b}, \mathrm{~d}, \mathrm{f}$ ), respectively. The boxes mark areas of selected for higher magnification. Macroscopically, the failure of both tensile specimens can be described as shear fracture at angles of about $45^{\circ}$ with respect to the loading direction. However, microscopically, there are differences between the two material conditions. The condition with only $1 \mathrm{~min}$ of natural aging predominantly shows smooth regions at low magnification (Figure 6a). These are zones of lower deformation (see also Figure $2 b$ ) and are enclosed by larger dimples (Figure $6 \mathrm{c}$ ). The regions of ductile fracture or cavities are predominantly formed at grain- or sub-grain boundaries and have a width of about $1 \mu \mathrm{m}$. Plastic straining during tensile testing widens the pores, which then leads to the initiation of cracks. This results in local necking at the cavities and suppresses further deformation. Finally, the remaining regions between pores are ruptured by the formation of shear lips. Most of the fracture surfaces, however, are characterized by smooth and less pronounced dimples (figure 6e). These regions considerably contribute to the macroscopically stable deformation and result in higher ductility, Figure 5b. Natural aging for $24 \mathrm{~h}$ prior to ECAP results in the formation of GP zones, which leads to a much more reduced (sub-)grain 
size. The increased numbers of precipitates, grain- and sub-grain boundaries is associated with a significantly more pronounced formation of dimples on the fracture surface, which therefore appears much rougher even at low magnifications (Figure 6b). Higher resolutions confirm reduced dimple sizes (Figure 6d) compared to Figure 6c. Regions with smooth surfaces are hardly observed. Throughout the entire fracture surface, the macroscopic deformation takes place by the formation of honeycomb structures. These dimples have a size range of about 50 to $100 \mathrm{~nm}$ (Figure 6f) with a strongly deformed topography and very fine intervoid ligaments. With increasing plastic strain during tensile testing, the deformation is concentrated in these regions. Due to the low supporting cross-section, the material tends to rapid local necking, which decreases macroscopic ductility. Finally, we note that the very small precipitates (in the size range of about $20 \mathrm{~nm}$ ) often act as internal notches and thus also lead to a further decrease of ductility (Figure 6f).
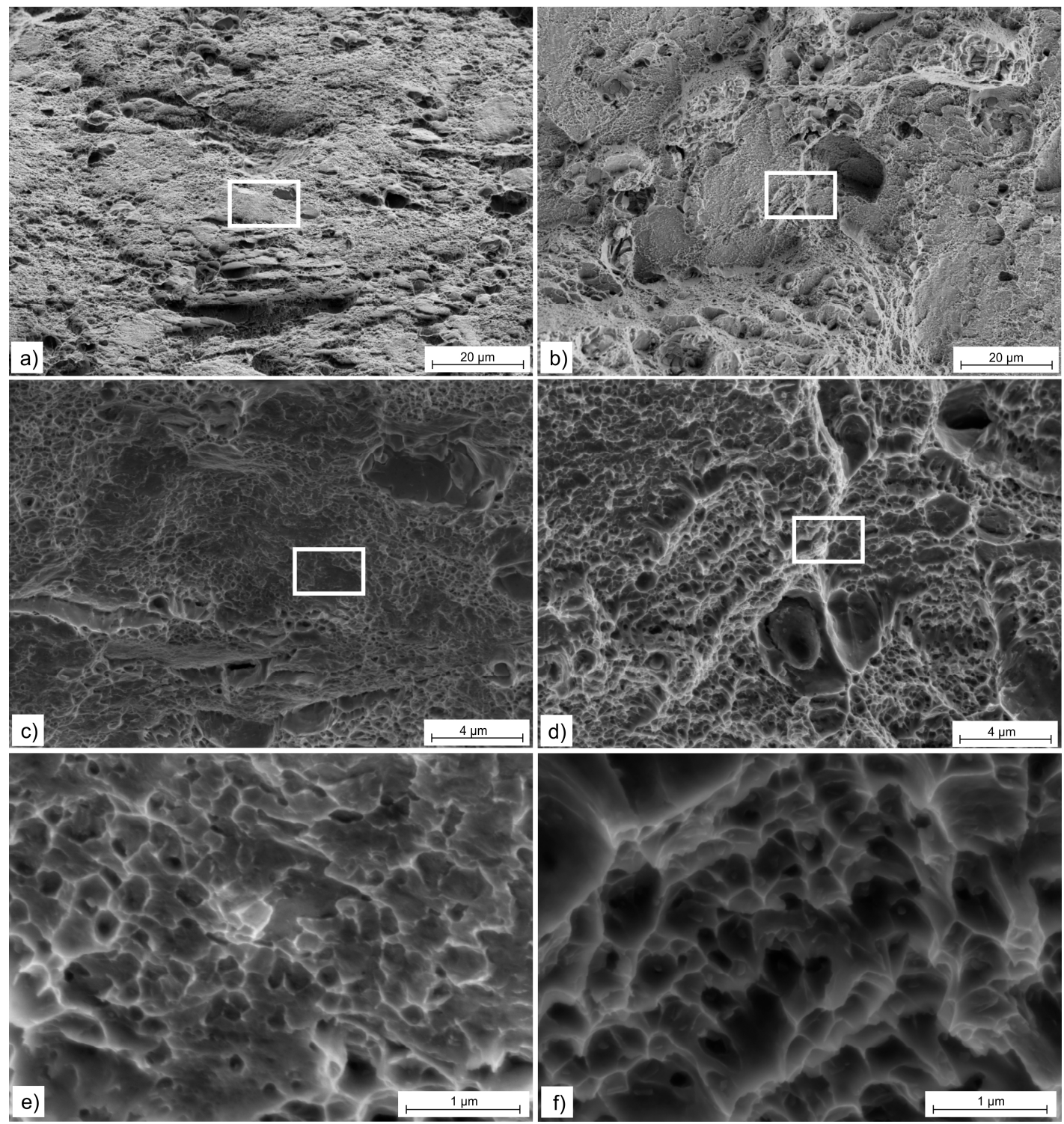

Figure 6. SEM micrographs of the fracture surfaces of AA7075 after one ECAP pass under cryogenic conditions with pre-ECAP natural aging of $(\mathbf{a}, \mathbf{c}, \mathbf{e}) 1 \mathrm{~min}$ and $(\mathbf{b}, \mathbf{d}, \mathbf{f}) 24 \mathrm{~h}$. Boxes mark the areas studied further at higher magnification. Natural aging prior to the deformation process results in a transition from a mixed fracture surface with smooth shear parts and dimple structures to fracture surfaces with very fine dimples. 


\section{Summary and Conclusions}

We have studied the influence of natural aging of a solid solution heat treated AA7075 alloy (prior to SPD) on the microstructure and the mechanical properties after equal-channel angular pressing. Because of an increased strain hardening capability of this alloy, low deformation temperatures result in an improved workability and increased ductility. Furthermore, low temperatures suppress the formation of precipitates. Therefore, we deformed the material at $-60{ }^{\circ} \mathrm{C}$ by ECAP and varied natural aging times prior to the deformation. We systematically investigated how the formation of strength-increasing precipitates influences the microstructure after SPD. As documented by transmission electron microscopy, low temperature ECAP combined with natural aging prior to the deformation results in relevant microstructural changes, i.e., grain refinement in the sub-micrometer range. A short pre-aging time results in the formation of a bimodal grain structure, where regions with fine-grained structures as well as regions with less deformation can be observed. When the aging time prior to deformation is increased, the number of precipitates is strongly increased. This leads to a more homogeneous microstructure with finer sub-structures. The documented microstructural changes are directly related to the post-ECAP mechanical properties that were further characterized by tensile testing. A reduced grain size leads to an increase of strength and to a reduced ductility and also affects fracture behavior.

Acknowledgments: The authors gratefully acknowledge funding by the German Research Foundation (Deutsche Forschungsgemeinschaft, DFG) within the framework of SFB 692 (project A1).

Author Contributions: Sebastian Fritsch and Martin Franz-Xaver Wagner conceived of this study. Sebastian Fritsch performed and analyzed the experiments, prepared the figures, and drafted the manuscript. Martin Franz-Xaver Wagner discussed the results and analysis and helped writing the manuscript.

Conflicts of Interest: The authors declare no conflict of interest.

\section{References}

1. Zhilyaev, A.; Langdon, T.G. Using high-pressure torsion for metal processing: Fundamentals and applications. Prog. Mater. Sci. 2008, 53, 893-979. [CrossRef]

2. Frint, S.; Hockauf, M.; Frint, P.; Wagner, M.F.-X. Scaling up Segal's principle of Equal-Channel Angular Pressing. Mater. Des. 2016, 97, 502-511. [CrossRef]

3. Valiev, R.Z.; Langdon, T.G. Principles of equal-channel angular pressing as a processing tool for grain refinement. Prog. Mater. Sci. 2006, 51, 881-981. [CrossRef]

4. Frint, P.; Hockauf, M.; Halle, T.; Strehl, G.; Lampke, T.; Wagner, M.F.-X. Microstructural features and mechanical properties after industrial scale ECAP of an Al-6060 alloy. Mater. Sci. Forum 2010, 667, 1153-1158. [CrossRef]

5. Zhao, Y.H.; Liao, X.Z.; Cheng, S.; Ma, E.; Zhu, Y.T. Simultaneously increasing the ductility and strength of nanostructured alloys. Adv. Mater. 2006, 18, 2280-2283. [CrossRef]

6. Valiev, R.Z.; Langdon, T.G. Developments in the use of ECAP processing for grain refinement. Rev. Adv. Mater. Sci. 2006, 13, 15-26.

7. Segal, V.M.; Reznikov, A.E.; Drobyshevskiy, A.E.; Kopylov, V.I. Plastic working of metals by simple shear. Russ. Metall. 1981, 1, 971-974.

8. Ferrasse, S.; Segal, V.M.; Alford, F.; Kardokus, J.; Strothers, S. Scale up and application of equal-channel angular extrusion for the electronics and aerospace industries. Mater. Sci. Eng. A 2008, 493, 130-140. [CrossRef]

9. Kim, W.J.; Kim, J.K.; Kim, H.K.; Park, J.W.; Jeong, Y.H. Effect of post equal-channel-angulat-pressing agingon the modified $7075 \mathrm{Al}$ alloy containing Sc. J. Alloys Compd. 2008, 450, 222-228. [CrossRef]

10. Zhao, Y.H.; Liao, X.Z.; Jin, Z.; Valiev, R.Z.; Zhu, Y.T. Microstructures and mechanical properties of ultrafine grained $7075 \mathrm{Al}$ alloy processed by ECAP and their evolutions during annealing. Acta Mater. 2004, 52, 4589-4599. [CrossRef] 
11. Fritsch, S.; Hunger, S.; Scholze, M.; Hockauf, M.; Wagner, M.F.-X. Optimisation of thermo mechanical treatments using cryogenic rolling and aging of the high strength aluminium alloy AlZn5.5MgCu (AA7075). Materialwiss. Werkstofftech. 2011, 42, 573-579. [CrossRef]

12. Fritsch, S.; Scholze, M.; Wagner, M.F.-X. Influence of thermally activated processes on the deformation behavior during low temperature ECAP. IOP Conf. Ser. Mater. Sci. 2016, 118, 1-13. [CrossRef]

13. Fritsch, S.; Hockauf, M.; Schönherr, R.; Hunger, S.; Meyer, L.W.; Wagner, M.F.-X. Investigation of the influence of ECAP and cryogenic rolling on the mechanical properties of the aluminium alloy 7075 . Materialwiss. Werkstofftech. 2010, 41, 697-703. [CrossRef]

14. Seeger, A.; Haasen, P. Density changes of crystals containing dislocations. Philos. Mag. 1958, 3, 470-485. [CrossRef]

15. Nabarro, F.R.N. Work hardening and dynamical recovery of FCC metals in multiple glide. Acta Metall. 1989, 37, 1521-1546. [CrossRef]

16. Magalhães, D.C.C.; Hupalo, M.F.; Cintho, O.M. Natural aging behavior of AA7050 Al alloy after cryogenic rolling. Mater. Sci. Eng. A 2014, 593, 1-7. [CrossRef]

17. Panigrahi, S.K.; Jayaganthan, R. Development of ultrafine grained high strength age hardenable Al 7075 alloy by cryorolling. Mater. Des. 2011, 32, 3150-3160. [CrossRef]

18. Deschamps, A.; Livet, F.; Bréchet, Y. Influence of predeformation on ageing in an Al-Zn-Mg alloy-I. Microstructure evolution and mechanical properties. Acta Mater. 1998, 47, 281-292. [CrossRef]

19. Panigrahi, S.K.; Jayaganthan, R. Effect of annealing on thermal stability, precipitate evolution, and mechanical properties of cryorolled Al 7075 alloy. Metall. Mater. Trans. A 2011, 42, 3208-3217. [CrossRef]

20. Rao, P.N.; Singh, D.; Jayaganthan, R. Mechanical properties and microstructural evolution of Al 6061 alloy processed by multidirectional forging at liquid nitrogen temperature. Mater. Des. 2014, 56, 97-104. [CrossRef]

21. Leacock, A.G.; Howe, C.; Brown, D.; Lademo, O.G.; Deering, A. Evolution of mechanical properties in a 7075 Al-alloy subject to natural ageing. Mater. Des. 2013, 49, 160-167. [CrossRef]

22. Fritsch, S.; Scholze, M.; Wagner, M.F.-X. Cryogenic forming of AA7075 by equal-channel angular pressing. Materialwiss. Werkstofftech. 2012, 43, 561-566. [CrossRef]

23. Kocks, U.F. Laws for work-hardening and low-temperature creep. J. Eng. Mater. Technol. ASME 1976, 98, 76-85. [CrossRef]

24. Iwahashi, Y.; Furukawa, M.; Horita, Z.; Nemoto, M.; Langdon, T.G. Microstructural characteristics of ultrafine-grained aluminum produced using equal-channel angular pressing. Metall. Mater. Trans. A 1998, 29, 2245-2252. [CrossRef]

25. Mughrabi, H. Dislocation wall and cell structures and long-range internal stresses in deformed metal crystals. Acta Metall. 1983, 31, 1367-1379. [CrossRef]

26. Xu, C.; Furukawa, M.; Horita, Z.; Langdon, T.G. The evolution of homogeneity and grain refinement during equal-channel angular pressing: A model for grain refinement in ECAP. Mater. Sci. Eng. A 2005, 398, 66-76. [CrossRef]

27. Dalla Torre, F.; Van Swygenhoven, H.; Victoria, M. Nanocrystalline electrodeposited Ni: Microstructure and tensile properties. Acta Mater. 2002, 50, 3957-3970. [CrossRef]

28. Wang, N.; Wang, Z.; Aust, K.T.; Erb, U. Isokinetic analysis of nanocrystalline nickel electrodeposits upon annealing. Acta Mater. 1997, 45, 1655-1669. [CrossRef]

(C) 2018 by the authors. Licensee MDPI, Basel, Switzerland. This article is an open access article distributed under the terms and conditions of the Creative Commons Attribution (CC BY) license (http:/ / creativecommons.org/licenses/by/4.0/). 